\title{
Correction \\ Correction: Li et al. Quantitative Evaluation of China's Pork Industry Policy: A PMC Index Model Approach. Agriculture 2021, 11, 86
}

\author{
Youzhu Li ${ }^{1} \mathbb{D}$, Rui He ${ }^{1}$, Jinsi Liu ${ }^{1}$, Chongguang $\mathrm{Li}^{2, *}$ and Jason Xiong ${ }^{3}$ \\ 1 College of Public Administration, Huazhong Agricultural University, Wuhan 430070, China; \\ liyz@mail.hzau.edu.cn (Y.L.); hr19930301@webmail.hzau.edu.cn (R.H.); \\ louis.hzau.edu.cn@webmail.hzau.edu.cn (J.L.) \\ 2 College of Economics and Management, Huazhong Agricultural University, Wuhan 430070, China \\ 3 Walker College of Business, Appalachian State University, Boone, NC 28608, USA; xiongjj@appstate.edu \\ * Correspondence: 1cg@mail.hzau.edu.cn
}

check for updates

Citation: Li, Y.; He, R.; Liu, J.; Li, C.; Xiong, J. Correction: Li et al. Quantitative Evaluation of China's Pork Industry Policy: A PMC Index Model Approach. Agriculture 2021, 11, 86. Agriculture 2022, 12, 113. https://doi.org/10.3390/ agriculture 12010113

Received: 16 December 2021 Accepted: 17 December 2021 Published: 14 January 2022

Publisher's Note: MDPI stays neutral with regard to jurisdictional claims in published maps and institutional affiliations.

Copyright: (C) 2022 by the authors. Licensee MDPI, Basel, Switzerland. This article is an open access article distributed under the terms and conditions of the Creative Commons Attribution (CC BY) license (https:// creativecommons.org/licenses/by/ $4.0 /)$.
The authors found some omissions and errors in the original paper [1].

The full details of the changes in the text are provided below.

The authors apologize for any inconvenience caused and state that the scientific conclusions are unaffected. The original article has been updated.

\section{Text Correction}

There were errors in the original article. The authors unintentionally missed Ruiz Estrada, M.A. et al.'s papers on PMC index models in the Journal of Policy Modeling and the International Journal of Economic Research, and Blei, D.M. et al.'s scholarly papers on LDA in the Journal of machine learning research in the reference. In addition, two scholars, Poland, O.F. and Suchman, E., are mentioned in the paper, and their references are therefore added.

A correction has been made to Introduction, Paragraph 1, and should read:

This paper mainly studies China's pork price regulation policies and their effects, uses text mining methods and LDA (Latent Dirichlet Allocation) [1] subject modeling, and combines a PMC (Policy Modeling Consistency) index model [2] to conduct quantitative analysis and evaluation of pork price regulation policies.

A correction has been made to Introduction, Section 1.2, Policy Evaluation Theory, Paragraph 1, and should read:

Since the 1970s, policy evaluation has gradually shifted from empirical standards to normative standards, emphasizing value judgments, represented by Poland's "three E" evaluation classification framework [9] and Suchman, E.'s five types of evaluation [10]. Hannoura et al. [11] believed that classical policy evaluation should start with revealing the causal mechanism of policies to judge the effects of policies and their impact on all social parties. The PMC index model is an international advanced policy text evaluation method. It is the consistency index model of policy modeling research proposed by Ruiz Estrada et al. based on the Omnia mobilis hypothesis. They believe that everything is connected and has the characteristics of the movement, and the variables should be widely taken into account when studying the policy model $[2,12]$.

\section{References}

Some references (Refs. $[1,2,9,10,12])$ have been added and the associated numbering has been updated accordingly.

1. Blei, D.M.; Ng, A.Y.; Jordan, M.I. Latent dirichlet allocation. J. Mach. Learn. Res. 2003, 3, 993-1022.

2. Ruiz Estrada, M.A. Policy modeling: Definition, classification and evaluation. J. Policy Modeling 2011, 33, 523-536. 
9. Poland, O.F. Program evaluation and administrative theory. Public Adm. Rev. 1974, 34, 333-338.

10. Suchman, E.A. Evaluative Research: Principles and Practice in Public Service E Social Action Programs; Russell Sage Foundation: New York, NY, USA, 1968.

12. Ruiz Estrada, M.A.; Yap, S.F.; Nagaraj, S. Beyond the ceteris paribus assumption: Modeling demand and supply assuming omnia mobilis. Int. J. Econ. Res. 2008, 5, 185-194.

\section{Reference}

1. Li, Y.; He, R.; Liu, J.; Li, C.; Xiong, J. Quantitative Evaluation of China's Pork Industry Policy: A PMC Index Model Approach. Agriculture 2021, 11, 86. [CrossRef] 